\title{
Aspergers syndrom i Sør-Trøndelag 2005-08
}

\author{
Sammendrag \\ Bakgrunn. Forekomsten av autisme- \\ spekterforstyrrelser har økt med en \\ faktor på ti i løpet av de siste årene. \\ Vi ønsket å se nærmere på forekomsten \\ i et geografisk definert område.
}

Materiale og metode. Vi har gjennomgått spesialisthelsetjenestenes pasientregistrering for barn 0-18 år med diagnosen Aspergers syndrom og uspesifisert gjennomgripende utviklingsforstyrrelse i Sør-Trøndelag per 1.1. 2005 og 1.1. 2008. Vi estimerte i tillegg forekomsten av høytfungerende barn med autisme per 1.1. 2008.

Resultater. I 2005 hadde 70 barn og ungdom diagnosen Aspergers syndrom, mot 121 i 2008 . For uspesifisert gjennomgripende utviklingsforstyrrelse var økningen fra 22 til 44 . I barneog ungdomspsykiatrien økte antallet med diagnosen Aspergers syndrom fra 51 i 2005 til 99 i 2008, i habiliteringstjenesten var det $32 \mathrm{i}$ både $2005 \mathrm{og}$ i 2008. Noen var registrert i begge tjenestene: 13 i 2005 og ti i 2008. I 2008 var samlet forekomst av diagnoser i autismespekteret med høyt funksjonsnivå (Aspergers syndrom, uspesifisert gjennomgripende utviklingsforstyrrelse og barn med autisme og høyt funksjonsnivå) $0,35 \%$ av populasjonen i alder 5-18 år. Nesten ingen barn var under fem år på måletidspunktet.

Fortolkning. I Sør-Trøndelag ligger forekomsten av autismespekterforstyrrelse med høyt funksjonsnivå i en størrelsesorden som er blitt rapportert fra internasjonale undersøkelser. Det kan forklares med økt oppmerksomhet på slike forstyrrelser og at mennesker med mindre uttalte symptomer fanges opp i større grad enn tidligere. Forskjellen i forekomst mellom helsetjenestene reflekterer ulike diagnostiske tradisjoner og endrede henvisningsrutiner.

\author{
Bernhard Weidle \\ b-weidle@online.no \\ Barne- og ungdomspsykiatrisk klinikk \\ St. Olavs hospital \\ Postboks 6810 Elgeseter \\ 7433 Trondheim \\ og \\ Institutt for nevromedisin
}

Norges teknisk-naturvitenskapelige universitet

\section{Torbjørn Gåsnes}

Barne- og ungdomspsykiatrisk klinikk

St. Olavs hospital

\section{Gunn Karin Skjetne}

Anne Lise Høyland

Habiliteringstjenesten for barn

Trondsletten habiliteringssenter

St. Olavs hospital

Begrepet «gjennomgripende utviklingsforstyrrelse» brukes synonymt med «autismespekterforstyrrelse» og inkluderer barneautisme, atypisk autisme, Retts syndrom, disintegrativ forstyrrelse i barndommen, Aspergers syndrom og uspesifisert gjennomgripende utviklingsforstyrrelse (pervasive developmental disorder not otherwise specified, PDD-NOS). Fellesnevner for tilstandene er en grunnleggende mangel på interesse for sosial omgang og/eller redusert evne til kommunikasjon og sosial interaksjon, kombinert med begrensede interesseområder og atferdsmønster.

Forekomsten av autismespektertilstander, inklusive Aspergers syndrom, er økt med en faktor på ti i epidemiologiske studier over hele verden i løpet av de siste ti årene. Eksempelvis rapporterte Scott og medarbeidere en prevalens av autismespekterforstyrrelser hos 5-11-åringer i Cambridgeshire, Storbritannia på nesten $0,6 \%$ (1). I en britisk kohortstudie med ca. 50000 barn i alderen 8-10 år fant man den hittil høyeste prevalensen av slike tilstander: $1,16 \%$ (2). I denne studien oppfylte $0,39 \%$ ICD-10-kriteriene for barneautisme og $0,77 \%$ kriteriene for de øvrige autismespekterforstyrrelsene.

Fra Norge foreligger en prevalensundersøkelse av autismespekterforstyrrelser i en barnepopulasjon (3-14 år) fra Akershus (3). Basert på grundige prosedyrer for identifikasjon og diagnostikk etter forskningskriteriene i ICD-10 fant man en prevalens for alle autismespekterforstyrrelser på 5,6 per 10000 (desember 1992). Barneautisme utgjorde den største undergruppen med 4,3 per 10000.

Av nyere undersøkelser foreligger en rapport fra SINTEF Helse med et prevalens- estimat basert på en spørreundersøkelse i desember 2005 som inkludererer svar fra 28 habiliteringstjenester for både barn og voksne (4). I rapporten ble konklusjonen en estimert forekomst av autismespekterforstyrrelser for hele befolkningen på 4,65 per 10000 innbyggere.

Posserud og medarbeidere (5) fant autistiske trekk (definert som høye skår på Autism Spectrum Screening Questionnaire) hos 2,7\% av 7-9-åringene som deltok på Barn i Bergen-prosjektet. Forfatterne tolket funnene som indikasjon på en gradvis overgang uten klart skille mellom dårlige sosiale ferdigheter og autismespekterforstyrrelser. Dermed kan små forskjeller i hvor man setter grensen mellom dårlig sosial fungering og autisme gi betydelige utslag ved beregning av forekomst av autisme.

Bakgrunnen for vår undersøkelse var et klinisk inntrykk av at diagnoser innen gruppen autismespekterforstyrrelser, særlig Aspergers syndrom, blir stilt stadig oftere. Vi ønsket å se nærmere på forekomsten $i$ et klinisk utvalg $\mathrm{i}$ et geografisk definert område (Sør-Trøndelag).

\section{Materiale og metode}

Vi har retrospektivt undersøkt data for alle barn i alderen 0-18 år med diagnosen Aspergers syndrom (F84.5 i ICD-10) og uspesifisert gjennomgripende utviklingsforstyrrelse (F84.9), henvist til spesialisthelsetjenesten og bosatt i Sør-Trøndelag fylke, hhv. 1.1. 2005 og 1.1. 2008. For 2008 beregnet vi også et estimat for forekomsten av barneautisme (F84.0) og høytfungerende barn med autisme. Begrepet «høytfungerende autisme» forekommer ikke som diagnose i

\section{Hovedbudskap}

- Vi har estimert at 3,5 av 1000 barn i alder 5-18 år i Sør-Trøndelag har en autismespekterforstyrrelse med høyt funksjonsnivå

- Det var en betydelig økt forekomst av disse diagnosene i 2008 sammenliknet med 2005

- Økningen skyldes sannsynligvis større oppmerksomhet på tilstandene og diagnostisering av mennesker med høyere funksjonsnivå

- Komorbide lidelser er hyppig og det er viktig å utrede og behandle disse 
Tabell 1 Barn og ungdom 0-18 år registrert med diagnosen F 84.5 Aspergers Syndrom og F 84.9 uspesifisert gjennomgripende utviklingsforstyrrelse (PDD-NOS) i spesialisthelsetjenesten i Sør-Trøndelag 1.1. 2005 og 1.1. 2008

\begin{tabular}{cccc}
\multicolumn{2}{c}{ Aspergers syndrom } & \multicolumn{2}{c}{ PDD-NOS } \\
2005 & 2008 & 2005 & 2008 \\
$(N=70)$ & $(N=121)$ & $(N=22)$ & $(N=44)$ \\
38 & 89 & 21 & 36 \\
19 & 22 & 1 & 6 \\
13 & 10 & 0 & 2
\end{tabular}

Behandlet kun i barne- og ungdomspsykiatrisk klinikk

Behandlet kun i habiliteringstjenesten

Behandlet i begge tjenester

ICD-10. Det anvendes for å karakterisere mennesker med autistisk forstyrrelse og evnenivå i normalområdet, og kodes under diagnosen barneautisme. I denne diagnosekoden skilles det ikke mellom evner på nivå med psykisk utviklingshemning og normalt evnenivå. I praksis ble denne diagnosen stilt når autismekriteriene var til stede, evnenivået lå i normalområdet, men språkutviklingen var signifikant forsinket. Språkkriteriet skilte gruppen fra Aspergers syndrom, der ICD-10 krever normal kognitiv utvikling og ingen signifikant språkforsinkelse.

Spesialisthelsetjenesten i Sør-Trøndelag har to dataregistre for denne diagnosegruppen, BUP-data for barne- og ungdomspsykiatrien og Pasientadministrativt system til pasientregistrering (PAS) for St. Olavs hospital, inklusive habiliteringstjenesten. Dataregistrene ble gjennomgått med tanke på diagnose, kjønnsfordeling, evnenivå, henvisningsgrunn og komorbiditet. De siste tre var kun kodet i BUP-data, men ikke i Pasientadministrativt system til pasientregistrering. Henvisningsgrunn for barn i habiliteringstjenesten ble hentet fra journalene.

To av forfatterne hadde kjennskap til mange av de gjeldende pasientene fra utredningen eller administrasjon av et gruppetilbud der ca. 50 ungdommer med diagnosen Aspergers syndrom hadde deltatt i tidsrommet 2000-08 (6). Noen få av disse var registrert under en annen diagnose. Der det var uklarheter omkring diagnosen, ble data kvalitetssikret med opplysninger fra pasientjournalene. Vi har ikke revurdert diagnosene; der det fremgikk av journalen at behandlerne vurderte at diagnosekriteriene i ICD-10 var til stede, inkluderte vi disse $\mathrm{i}$ materialet. For å beregne prevalens brukte vi innbyggertall fra Statistisk sentralbyrå 1.1. 2005 og 1.1. 2008 (7).

\section{Etikk}

Undersøkelsen er godkjent av Regional etisk komité i Sør-Trøndelag og forelagt personvernombudet, som ikke fant prosjektet fremleggelsespliktig. Personvernombudet la til grunn at det ikke opprettes manuelt personregister som inneholder sensitive personopplysninger og at taushetsplikten ikke var til hinder for å hente ut journalopplysninger og sammenstille dem for anonym utlevering til prosjektleder (Gåsnes) i og med at innsyn i pasientjournal og identifiserbare opplysninger bare ble gjort av klinikere (Høyland og Weidle) som uansett har innsyn i disse dokumentene som en del av arbeidsoppgavene som pasientansvarlig lege.

\section{Resultater}

1.1. 2005 hadde 70 barn og unge bosatt $i$ Sør-Trøndelag fylke diagnosen Aspergers syndrom (tab 1). Det samlede innbyggertallet var 67533 personer i alderen 0-18 år, noe som gir en punktprevalens på $0,10 \%$. 1.1.2008 hadde 121 barn og unge diagnosen Aspergers syndrom, mens befolkningsgruppen $0-18$ år var på 68781 . Forekomsten var dermed $0,18 \%$. Antall barn og unge som hadde fått diagnosen Aspergers syndrom i barne- og ungdomspsykiatrisk klinikk, økte fra 38 i 2005 til 89 i 2008, mens det var nærmest konstant $\mathrm{i}$ habiliteringstjenesten.

Tilsvarende var 44 barn i alderen $0-18$ år 1.1. 2008 registrert med diagnosen uspesifisert gjennomgripende utviklingsforstyrrelse (prevalens 0,06\%). I 2005 var antallet med denne diagnosen 22 (prevalens 0,03\%). Samlet forekomst av diagnosene Aspergers syndrom og uspesifisert gjennomgripende utviklingsforstyrrelse i Sør-Trøndelag var dermed økt til $165(0,24 \%)$, fra $92(0,14 \%)$ tre år tidligere.

1.1. 2008 var 41 barn og unge (0-18 år) med barneautisme registrert i habiliteringstjenesten. 14 av disse vurderte vi til å være i gruppen høytfungerende barn med autisme. barneautisme registrert, begge hadde fått diagnosen $\mathrm{i}$ habiliteringstjenesten og var også registrert der.

\section{Samlet forekomst}

Hvis man inkluderer de 14 høytfungerende barna med autisme i estimatet for forekomst av autismespekterforstyrrelse med høyt funksjonsnivå, blir tallet 179, dvs. en prevalens på $0,26 \%$. Bare et fătall barn hadde fått fastlagt diagnosen før sjuårsalderen. Kun to var under fem år ved tidspunktet for beregning av prevalens i 2008 og ingen i 2005. Basert på antall barn i aldersgruppen 5-18 år (51 227) beregnes samlet forekomst av autismespekterforstyrrelser med høyt funksjonsnivå per 1.1. 2008 i Sør-Trøndelag fylke til 0,35\%. I BUP-data var kun to barn med diagnosen

\section{Kjønnsfordeling}

I 2008 var 104 gutter og 17 jenter med Aspergers syndrom $(6: 1)$ og 33 gutter og 11 jenter med uspesifisert gjennomgripende utviklingsforstyrrelse $(3: 1)$ registrert. Samlet for begge diagnosegrupper var kjønnsfordelingen $5: 1$.

\section{Evnenivå}

I tråd med diagnosekriteriene hadde alle med diagnosen Aspergers syndrom IQ over, i eller litt under normalområdet (tab 2). For barn med diagnosen uspesifisert gjennomgripende utviklingsforstyrrelse var intelligensnivå generelt lavere, hos $42 \%$ litt under normalområdet, mens $13 \%$ hadde lav IQ.

\section{Komorbiditet}

Tabell 3 gir en oversikt over tilleggsdiagnoser som var registrert i BUP-data. Hyperkinetiske forstyrrelser var den hyppigste tilleggsdiagnosen: 40 (40,4\%) barn med Aspergers syndrom og åtte $(21,1 \%)$ med uspesifisert gjennomgripende utviklingsforstyrrelse. Halvparten av dem med Aspergers syndrom hadde registrert komorbiditet; 29 (29,3\%) hadde registrert én, $19(19,2 \%)$ to, og to $(2 \%)$ hadde tre komorbide diagnoser. Gruppen uspesifisert gjennomgripende utviklingsforstyrrelse hadde nesten samme mønster: totalt var 17 $(44,7 \%)$ registrert med komorbiditet, 11 $(28,9 \%)$ hadde registrert én og seks $(15,8 \%)$ to eller tre komorbide diagnoser.

\section{Henvisningsgrunn}

Atferdsvansker hos 47 (47,5\%) og hyperaktivitet/konsentrasjonsvansker hos 30 (30,3\%) var de hyppigste henvisningsgrunner for barn som var registrert med diagnosen Aspergers syndrom i barne- og ungdomspsykiatrisk klinikk per 1.1.2008. Autistiske trekk som en av henvisningsgrunnene var angitt for 19 $(19,2 \%)$ og som eneste grunn kun hos sju $(7,1 \%)$. For barn som var registrert med diagnosen Aspergers syndrom i habiliteringstjenesten, var autistiske trekk én av henvisningsgrunnene hos $20(62,5 \%)$ og eneste henvisningsgrunn hos $13(40,6 \%)$. Ti pasienter var registrert $\mathrm{i}$ begge tjenester.

\section{Diskusjon}

Vi fant at 0,35\% i aldersgruppen 5-18 år i Sør-Trøndelag var diagnostisert med en autismespekterforstyrrelse med høyt funksjonsnivå per 1.1. 2008. Prevalensen i populasjonen som var registrert i spesialisthelsetjenesten på dette tidspunkt, representerer ikke den reelle prevalensen i befolkningen, men siden ingen andre institusjoner i fylket stilte denne diagnosen, kan det likevel gi et estimat for reell prevalens. Vi fant en betydelig høyere andel av disse typer forstyrrelser enn det som er rapportert tidligere i Norge. I Sponheim \& Skjeldals prevalensundersøkelse fra Akershus i 1992 var det kun to barn med Aspergers syndrom blant de 34 pasientene med autismespekterforstyrrelse (3). Forfatterne bemerket at denne diagnosen var 
lite kjent $\mathrm{i}$ begynnelsen av studien. Dessuten inkluderte screeningsprosedyrene ikke samarbeid med lærere i normale skoleklasser, slik at barn med Aspergers syndrom sannsynligvis ikke ble fanget opp.

SINTEFs prevalensberegning fra 2005 som viste $0,046 \%$ for hele spekteret av autismeforstyrrelser, er mindre enn en tiendedel av det som rapporteres fra internasjonale undersøkelser (4). SINTEF-studien har benyttet tall for hele befolkningen ( $0-100$ år) i prevalensberegningen, mens de fleste siterte epidemiologiske undersøkelser har beregnet prevalens basert på andelen i barne- eller ungdomspopulasjonen. Forfatterne kommenterte at det lave estimatet kan skyldes at habiliteringsteamene for det meste har oversikt over de yngste barna. I tillegg er det grunn til å tro at man har betydelig underdiagnostisering av høytfungerende voksne med autismespekterforstyrrelse, samtidig som mange i aldersgruppen $0-6$ år ennå ikke er blitt identifisert.

Forekomsten av autismespekterforstyrrelse med høyt funksjonsnivå i Sør-Trøndelag ligger i samme størrelsesorden som det som ble rapportert fra internasjonale undersøkelser. Økningen synes å gjenspeile den internasjonale trenden med økt oppmerksomhet på denne type forstyrrelser og en tolkning av diagnosekriteriene som inkluderer mennesker med mindre uttalte symptomer.

\section{Hvilken diagnose?}

Validiteten av diagnosen Aspergers syndrom er lav. Det foreligger flere diagnosesystemer med til dels konkurrerende kriterier. Ulike forskningsmiljøer er uenige om hvordan man skal avgrense høytfungerende barn med autisme, Aspergers syndrom og uspesifisert gjennomgripende utviklingsforstyrrelse fra hverandre. Wing foreslo begrepet Aspergers syndrom som del av et autismespekter med normale intellektuelle evner (8). For å skille Aspergers syndrom fra barneautisme fokuserer DSM-IV på alder ved symptomstart og ICD-10 på språkforsinkelse. Klin og medarbeidere (9) delte kognitivt høyt fungerende mennesker med alvorlig sosial funksjonsvikt inn i gruppene autisme, Aspergers syndrom og uspesifisert gjennomgripende utviklingsforstyrrelse på bakgrunn av tre ulike diagnosesystemer: DSM-IV-kriterier, språkforsinkelseskriteriet og et nytt system. Dette nye systemet er basert på Aspergers opprinnelig beskrevne «prototyper», der det legges vekt på ensidig ordrikdom og begrensede interesseområder som er til hinder for læring eller sosial kommunikasjon (9). Den diagnostiske overensstemmelsen mellom de tre systemene var lav.

Basert på 43 prevalensundersøkelser publisert i perioden 1966-2008 beregnet Fombonne forekomsten av autismespekterforstyrrelser til å være $0,6-0,7 \%(10)$. Barneautisme/autistisk forstyrrelse (voksne) og atypisk autisme utgjorde $0,1-0,2 \%$, Aspergers syndrom, autisme med høyt funk-

Tabell 2 Evnenivå hos barn og ungdom 0-18 år registrert med diagnosen Aspergers syndrom ( $n=99$ ) og uspesifisert gjennomgripende utviklingsforstyrrelse (PDD-NOS) ( $n=38$ ) i barneog ungdomspsykiatrisk klinikk i Sør-Trøndelag per 1.1. 2008

\begin{tabular}{llcc} 
Evnenivå & Aspergers Syndrom & $\begin{array}{c}\text { PDD-NOS } \\
\mathrm{n}(\%)\end{array}$ \\
Svært høyt & $\mathrm{IQ} \geq 130$ & $1(1)$ & 0 \\
\hline Høyt & $\mathrm{IQ} 115-129$ & $12(12,1)$ & $1(2,6)$ \\
\hline Normalt & $\mathrm{IQ} 85-114$ & $64(64,7)$ & $12(31,6)$ \\
Litt under normalt & $\mathrm{IQ} 70-84$ & $8(8,1)$ & $16(42,1)$ \\
Lavt & $\mathrm{IQ}<69$ & 0 & $5(13,2)$ \\
\hline Ukjent/ikke angitt & & $14(14,1)$ & $4(10,5)$
\end{tabular}

sjonsnivå og uspesifisert gjennomgripende utviklingsforstyrrelse $0,4-0,6 \%$. Internasjonalt har diagnosegruppen uspesifisert gjennomgripende utviklingsforstyrrelse $ø \mathrm{kt}$ mest. Denne diagnosen anvendes hvis barnet vurderes til å ha en autismespekterforstyrrelse, men ikke fyller alle kriterier for en spesifisert tilstand i spekteret. Fombonne beregnet prevalens av denne gruppen til $0,3 \%(10)$

I vår undersøkelse var forekomsten betydelig lavere $(0,06 \%)$, selv om det var denne gruppen som hadde den relativt største økningen. Forekomsten av Aspergers syndrom derimot estimerte Fombonne til $0,06 \%$. Dette lave estimatet står i kontrast til den skandinaviske diagnosetradisjonen, representert av for eksempel Ehlers \& Gillberg som i sin undersøkelse av 8-16-åringer i Göteborg anslo prevalens av Aspergers syndrom til $0,3 \%$ (11). Kadesjø og medarbeidere anga $0,48 \%$ (12) og Ellefsen og medarbeidere $0,26 \%$ i en undersøkelse fra Færøyene (13). I Sør-Trøndelag var Aspergers syndrom med $0,18 \%$ den mest stilte diagnosen $\mathrm{i}$ autismespekteret med høyt funksjonsnivå. Forekomsten ligger i underkant av estimatene fra de nevnte populasjonsbaserte skandinaviske undersøkelsene (11-13). I og med at prevalenstallene for den høytfungerende andelen av autismespekteret er relativt lik i de fleste nyere undersøkelser, er det nærliggende å tro at en stor andel av de barna som fikk diagnosen Aspergers syndrom i den skandinaviske tradisjonen, ville fått diagnosen autisme med høyt funksjonsnivå eller uspesifisert gjennomgripende utviklingsforstyrrelse $\mathrm{i}$ den øvrige europeiske og den nordamerikanske diagnostiske tradisjonen.

Det er å håpe at de planlagte revisjoner av diagnosesystemene ICD-10 og DSM-IV tilbyr mer presise og internasjonalt aksepterte retningslinjer for diagnostikk, som igjen vil være en forutsetning for forskningsmessig validering av tilstandene. I Norge er prosesser i gang som skal bidra til en mer enhetlig diagnostisering. I rammen av etablerte kompetansenettverk for autisme, AD/HD, Tourettes syndrom og narkolepsi holdes det konsensuskonferanser både i Helse Sør-Øst og i Helse Midt-Norge.

\section{Ulikhet mellom tjenestene}

Økningen i antallet barn og unge som fikk diagnosen Aspergers syndrom fra 2005 til 2008 var begrenset til barn diagnostisert i barne- og ungdomspsykiatrien, mens antallet i habiliteringstjenesten var tilnærmet uforandret. For uspesifisert gjennomgripende utviklingsforstyrrelse var forskjellen mindre utpreget. Dette kan representere reelle forskjeller i diagnostisk praksis. Selv om tjenestene har samarbeid og kjenner til hverandres utredningsmodeller kan det se ut som om kriteriene for å stille diagnosen ble vurdert forskjellig, noe som understreker viktigheten av rutiner for en felles diagnostiseringspraksis i hele spesialisthelsetjenesten.

Ulikheten mellom tjenestene kan også bero på endring i henvisningsrutinene. I SørTrøndelag ble barn med mistanke om forstyrrelse innen autismespekteret tidligere henvist til utredning i habiliteringstjenesten. Gjenkjenningskompetansen i barne- og ungdomspsykiatrien var dermed lav. Denne praksisen ble endret i 1998. Barn som var henvist barne- og ungdomspsykiatrisk klinikk pga. andre problemer, ble ikke lenger henvist videre til habiliteringstjenesten, men utredet $\mathrm{i}$ barne- og ungdomspsykiatrien ved

Tabell 3 Komorbiditet hos barn og ungdom 0-18 år registrert med diagnosen Aspergers syndrom eller uspesifisert gjennomgripende utviklingsforstyrrelse (PDD-NOS) ( $N=137)$

i barne- og ungdomspsykiatrisk klinikk i Sør-Trøndelag per 1.1. 2008. Kun tilleggsdiagnoser som ble stilt hos flere enn én pasient er listet

Tilleggsdiagnose $n(\%)$

$\mathrm{AD} / \mathrm{HD}$ $25(18,2)$

AD/HD hovedsaklig

oppmerksomhetssvikt

Hyperkinetisk atferds-

forstyrrelse

Tourettes syndrom

Kroniske tics

Tvangslidelse

Depresjon

Psykisk utviklingshemning

(kun innen gruppen PDD-NOS) 3 (2,2) 
mistanke om autismespekterforstyrrelse. I tillegg ble også henvisningspraksis for barn med andre nevropsykiatriske lidelser (som $\mathrm{AD} / \mathrm{HD}$ og Tourettes syndrom) endret i 2003, slik at disse barna skulle kanaliseres til barne- og ungdomspsykiatrien. Hyppig komorbiditet og overlappende symptomer mellom disse tilstandene kan også ha bidratt til økningen i antall barn med autismespektertilstander som ble diagnostisert i barneog ungdomspsykiatrisk klinikk. At mistanke om autisme eller «autistiske trekk» var henvisningsgrunn hos to tredeler av dem med diagnosen Aspergers syndrom i habiliteringstjenesten per 1.1.2008, men kun hos en femdel av pasientene i barne- og ungdomspsykiatrien, kan støtte denne hypotesen.

\section{Tilleggssykdommer}

Omtrent halvparten av barna med Aspergers syndrom og uspesifisert gjennomgripende utviklingsforstyrrelse hadde minst én tilleggsdiagnose, oftest hyperkinetisk forstyrrelse eller Tourettes syndrom. Dette er i tråd med det som er rapportert fra andre undersøkelser (14). For de øvrige tilstandene har vi betydelig underrapportering sammenliknet med andre undersøkelser, der spesielt angstlidelser og depresjon har høy forekomst. I ICD-10 er ett av de diagnostiske kriteriene for Aspergers syndrom at ingen annen tilstand kan forklare symptomene bedre. Komorbide tilstander som $\mathrm{AD} / \mathrm{HD}$ skal derfor ikke diagnostiseres samtidig, men man skal velge hvilken tilstand som forklarer symptomene best. Dette har bidratt til underrapportering av komorbide tilstander. Behandlerne vil ofte tolke tilleggssymptomer som en del av den autistiske grunnproblematikken. De fleste eksperter, for eksempel Ghaziuddin (15), anbefaler å utrede for samtidig forekommende lidelser og at en tilleggsdiagnose settes dersom de diagnostiske kriteriene er til stede. $\AA ̊$ avvise for eksempel en AD/HD-diagnose hos et barn med autismespekterforstyrrelse ville være klinisk lite meningsfullt og redusere muligheten for både å forstå og behandle symptomene mer presist.

\section{Studiens begrensninger}

I motsetning til BUP-data omfattet habiliteringstjenestens dataregister ikke saker som var avsluttet og tilbakeført til førstelinjen. På bakgrunn av kjennskap til pasientene fra klinisk arbeid mener vi å ha registrert alle i diagnosegruppen Aspergers syndrom og uspesifisert gjennomgripende utviklingsforstyrrelse også i habiliteringstjenesten. Tallet for diagnosegruppen barneautisme (F84.0) er et underestimat, basert på barn under utredning eller behandling ved habiliteringstjenesten.

En annen begrensning er at det ikke foreligger standardiserte utredningsprosedyrer.
Diagnosene ble som regel stilt etter tverrfaglig utredning. Screeningsinstrumenter (for eksempel Autism Spectrum Screening Questionnaire) (5), anamnese med foresatte, informasjonsinnhenting fra barnehage, skole eller pedagogisk-psykologisk tjeneste (PPT), somatisk undersøkelse, testing av evnenivå og observasjon/vurderingssamtale med barnet ble brukt i diagnostikken. Utredningsinstrumenter som ADI-R (Autism Diagnostic Interview-Revised) eller ADOS (Autism Diagnostic Observation Schedule) (16) ble kun anvendt hos et mindretall og oftere ved utredning $\mathrm{i}$ habiliteringstjenesten. Endelig diagnose ble stilt etter en samlet vurdering opp mot de diagnostiske kriteriene i ICD-10.

\section{Konklusjon}

I vår analyse av diagnostisk praksis i SørTrøndelag har vi funnet økende forekomst av autismespekterforstyrrelser med høyt funksjonsnivå hos barn og ungdom. Den samme trenden er blitt rapportert fra internasjonale undersøkelser. Sannsynligvis skyldes dette økt oppmerksomhet på autismespektertilstander og inklusjon av mennesker med høyere funksjonsnivå. En forekomst av disse forstyrrelsene på $0,35 \%$ av barnepopulasjonen 5-18 år viser at denne gruppen er større enn tidligere rapportert i Norge. Både antallet og at det er høy andel av komorbide tilstander må tas hensyn til ved utforming av tjenestetilbudet til denne gruppen.

Vi takker Thomas Jozefiak og Inger Johanne Bakken for gjennomlesing og nyttige kommentarer.

Oppgitte interessekonflikter: Ingen

\section{Litteratur}

1. Scott FJ, Baron-Cohen S, Bolton P et al. Brief report: prevalence of autism spectrum conditions in children aged 5-11 years in Cambridgeshire, UK. Autism 2002; 6: $231-7$

2. Baird G, Simonoff E, Pickles A et al. Prevalence of disorders of the autism spectrum in a population cohort of children in South Thames: the Special Needs and Autism Project (SNAP). Lancet 2006; 368: $210-5$.

3. Sponheim E Skjeldal O. Autism and related disorders: epidemiological findings in a Norwegian study using ICD-10 diagnostic criteria. J Autism Dev Disord 1998; 28: 217-27

4. Hem KG, Husum TL. Prevalens av autisme. Rapport A7249. Oslo: SINTEF Helse, 2008.

5. Posserud MB, Lundervold AJ, Gillberg C. Autistic features in a total population of 7-9-year-old children assessed by the ASSQ (Autism Spectrum Screening Questionnaire). J Child Psychol Psychiatry 2006; 47: 167-75.

6. Weidle B, Bolme B, Hoeyland AL. Are peer support groups for adolescents with Asperger's syndrome helpful? Clin Child Psychol Psychiatry 2006; 11: 45-62.

7. Statistisk sentralbyrå. http://statbank.ssb.no/ statistikkbanken/Default_FR.asp?PXSid=0\&nvl=true \&PLanguage $=0 \&$ tilside $=$ selectvarval/define.asp\& Tabellid=07459).

8. Wing L. Asperger's syndrome: a clinical account. Psychol Med 1981; 11: 115-29.

9. Klin A, Pauls D, Schultz R et al. Three diagnostic approaches to Asperger syndrome: implications for research. J Autism Dev Disord 2005; 35 221-34.

10. Fombonne E. Epidemiology of pervasive developmental disorders. Pediatr Res 2009; 65: 591-8.

11. Ehlers S, Gillberg C. The epidemiology of Asperger syndrome. A total population study. J Child Psychol Psychiatry 1993; 34: 1327-50.

12. Kadesjö B, Gillberg C, Hagberg B. Brief report: autism and Asperger syndrome in seven-year-old children: a total population study. J Autism Dev Disord 1999; 29: 327-31

13. Ellefsen A, Kampmann H, Billstedt E et al. Autism in the Faroe Islands: an epidemiological study. J Autism Dev Disord 2007; 37: 437-44.

14. Simonoff E, Pickles A, Charman T et al. Psychiatric disorders in children with autism spectrum disorders: prevalence, comorbidity, and associated factors in a population-derived sample. J Am Acad Child Adolesc Psychiatry 2008; 47: 921 -9

15. Ghaziuddin M. 2005. Mental health aspects of autism and Asperger syndrome. Philadelphia, PA: Jessica Kingsley Publishers, 2005.

16. Lord C, Rutter M, Goode S et al. Autism diagnostic observation schedule: a standardized observation of communicative and social behavior. J Autism Dev Disord 1989; 19: 185-212.

Mottatt 26.11. 2009, første revisjon innsendt 19.5. 2009, godkjent 11.11. 2010. Medisinsk redaktør Siri Lunde. 